\title{
The role of endothelial dysfunction and inflammation in young-onset hypertension
}

\author{
Serkan Gokaslan, ${ }^{1}$ Cigdem Ozer Gokaslan, ${ }^{2}$ Sefa Celik ${ }^{3}$ \\ ${ }^{1}$ Department of Cardiology, Faculty of Medicine; ${ }^{2}$ Department of Radiology; and ${ }^{3}$ Department of Biochemistry, Faculty of \\ Medicine, Afyonkarahisar Health Sciences University, Afyonkarahisar, Turkey
}

\begin{abstract}
Young-onset hypertension is defined as hypertension seen in patients under 40 years of age. The relationship between hypertension and inflammation has been identified. In hypertensive patients, YKL-40 has been shown to be increased by endothelial dysfunction as a local secreted mediator. Vaspin, an adipokine, is derived from adipose tissue and irreversibly inhibits serine proteases. It has been reported that vaspin may act as an anti-inflammatory agent and increases endothelial-dependent relaxation, also has a positive effect on nitric oxide bioavailability, which is important in the etiology of endothelial dysfunction. In clinical practice, some indirect and practical methods may help to evaluate endothelial functions, including flow-mediated dilatation (FMD), which is considered to be the most practical and effective method. The present study was performed to determine the circulating YKL-40 and vaspin levels in young-onset hypertensive patients and healthy subjects and to reveal their relationships with vascular function evaluated by FMD. We enrolled 24 patients diagnosed with young-onset hypertension and 22 volunteers without hypertension. The plasma levels of YKL-40 and vaspin were determined using an enzyme-linked immunosorbent assay and quantitative enzyme-linked immunoassay, respectively. FMD was measured using a Doppler ultrasound device. Compared with those in normotensive controls, the plasma levels of YKL-40 were significantly higher, and FMD values were significantly lower in patients with young-onset hyperten-

Correspondence: Serkan Gokaslan, Afyonkarahisar Sağlık Bilimleri Üniversitesi Hastanesi, Ali Çetinkaya Kampusü, Dörtyol mah. 2078 sok. No. 3/4 Afyonkarahisar, Turkey.

Tel.: +39.05058308174 - Fax: +39.272.2463344

E-mail: serkangokaslan6@gmail.com

Key words: Flow-mediated dilatation; young-onset hypertension; inflammation markers. sion $(\mathrm{P}<0.05)$. The plasma levels of YKL-40 were also negatively correlated with FMD. However, no statistically significant difference was noted in the levels of vaspin between the two groups $(\mathrm{P}=0.531)$. In this study, decreased FMD and increased levels of YKL-40 were associated with endothelial dysfunction and inflammation in patients with young-onset hypertension, suggesting the role of these factors in the etiology of hypertension.
\end{abstract}

Acknowledgments: we would like to thank Prof Dr. Ismet Dogan for his help in the statistical analysis of our study.

Contributions: SG designed the study; SG and COG investigated and supervised the findings of this work; SC verified the analytical methods. All authors discussed the results and contributed to the final manuscript.

Conflict of interests: the authors declare no potential conflict of interests.

Availability of data and materials: data and materials of the study can be obtained from the authors, if there is a valid reason.

Ethics approval and consent to participate: all participants gave their informed consent, and the ethics committee of the Medical Faculty of Afyonkarahisar Health Sciences University approved the study with the number: 2019/333.

Received for publication: 2 March 2020.

Revision received: 14 April 2020.

Accepted for publication: 14 April 2020.

This work is licensed under a Creative Commons Attribution NonCommercial 4.0 License (CC BY-NC 4.0).

${ }^{\circ}$ Copyright: the Author(s), 2020

Licensee PAGEPress, Italy

Italian Journal of Medicine 2020; 14:151-155

doi:10.4081/itjm.2020.1272

\section{Introduction}

Hypertension is the most common cardiovascular risk factor that contributes to morbidity and mortality worldwide, and approximately $90 \%$ of cases are classified as essential hypertension because the exact cause of their disease is unknown. ${ }^{1,2}$ Young-onset hypertension is defined as hypertension seen in patients under 40 years of age and has been shown to present with target organ damage similar to that observed in later stages of hypertension. ${ }^{3,4}$ The development of hypertension is a complex mechanism involving many factors. The relationship between hypertension and inflammation has been identified, but it remains unclear whether inflammation is the cause or consequence of hypertension. ${ }^{5}$ Increased inflammatory status in hypertensive patients occurs not only due to the increased excessive pressure load and subsequent activation of systemic pathways but also as a result of locally secreted mediators. ${ }^{6}$

In hypertensive patients, YKL-40 has proven to be increased by endothelial dysfunction as a local se- 
creted mediator, and it is considered to be an indicator of subclinical diseases related to vascular endothelial damage. ${ }^{7,8}$ In endothelial dysfunction, increased YKL40 levels seem to be related to cell migration and organization and tissue reconstruction as a response to endothelial damage. ${ }^{9,10}$ Vaspin, an adipokine, is derived from adipose tissue and irreversibly inhibits serine proteases. ${ }^{11}$ However, little is known about the effects of vaspin on the pathogenesis of hypertension. ${ }^{12} \mathrm{~A}$ variety of evidence has shown that vaspin suppresses inflammatory cytokine release and may act as an anti-inflammatory agent. ${ }^{13-15}$

In clinical practice, there is no direct method to measure endothelial functions; however, some indirect and practical methods may help to evaluate these functions, including flow-mediated dilatation (FMD), which is considered as the most practical and effective method. ${ }^{16,17}$ This is a noninvasive ultrasonographic evaluation based on endothelium-dependent arterial vasodilatation. ${ }^{18}$

The present study was performed to determine the circulating YKL-40 and vaspin levels in young-onset hypertensive patients and healthy subjects and to reveal their relationships with vascular function evaluated by FMD.

\section{Materials and Methods}

Between December 2018 and September 2019, 24 patients with a diagnosis of young-onset hypertension, all aged over 18 and under 40 years, and 22 volunteers without hypertension were included in the study. Patients with rheumatic disease, hyperlipidemia, and acute or chronic infection and those receiving medications that could influence vascular function were excluded from the study in addition to smokers. Both groups were matched for age and gender. White blood cell levels, C-reactive protein levels, and sedimentation rates of all participants were within normal limits. All participants gave their informed consent, and the ethics committee of the Medical Faculty of Afyonkarahisar University of Health Sciences approved the study .

The plasma levels of YKL-40 (gp-39) were determined using an enzyme-linked immunosorbent assay (ELISA) kit (Elabscience, Texas, USA) as per the manufacturer's recommendations. Absorbance was measured at $450 \mathrm{~nm}$ using a spectrophotometer (BioTek, Epoch Microplate Spectrophotometer, Winooski, Vermont, USA). The sensitivity, detection range and coefficient of variation were $37.50 \mathrm{pg} / \mathrm{mL}$, $62.50-4000 \mathrm{pg} / \mathrm{mL}$ and $<10 \%$ respectively. The level of vaspin was measured using a quantitative ELISA kit (Elabscience, Texas, USA), and absorbance was measured at $450 \mathrm{~nm}$ wavelength. The sensitivity, detection range and coefficient of variation were 37.50 $\mathrm{pg} / \mathrm{mL}, 62.50-4000 \mathrm{pg} / \mathrm{mL}$, and $<10 \%$ respectively.
For the FMD measurements, participants were examined following fasting and avoiding smoking and consumption of caffeine for at least $12 \mathrm{~h}$. An Aplio MX duplex Doppler ultrasound device (Toshiba, Japan, 2010) and a 7.5 MHz probe were used to measure brachial FMD. In the supine position, the basal measurements of the right brachial artery were longitudinally recorded in the end-diastole, approximately $5 \mathrm{~cm}$ proximally to the antecubital fossa, and the cuff was placed in the proximal portion of the brachial artery. The Doppler probe was inflated until no blood flow from the brachial artery was detected and held at this pressure for $5 \mathrm{~min}$. The cuff was then deflated, and the arterial diameter was measured 45 to $60 \mathrm{~s}$ after the cuff was released. FMD, showing the brachial artery vasodilator response to reactive hyperemia, was calculated as the maximum percentage change in the internal diameter of the brachial artery after basal and reactive hyperemia $[$ FMD $(\%)=($ maximum diameter - diameter at rest)*100/(diameter at rest)]..$^{18,19}$

\section{Statistical analysis}

Statistical analysis was performed using the Statistical Package for the Social Sciences (SPSS Inc., version 21.0 Chicago, IL, USA). The normally distributed data were expressed as mean \pm standard deviation (SD) and non-normally distributed data as median (25\%-75\%) values. The comparison between categorical and continuous variables was performed using the chi-square and Mann-Whitney U tests, respectively. The association between YKL-40, vaspin and FMD was investigated through Spearman's correlation coefficient. A P value of $<0.05$ was considered as statistically significant. An a priori power analysis could not be conducted due to the unavailability of pilot data. Therefore, a post-hoc power analysis was performed to confirm that the current study had adequate power $(99 \%)$.

\section{Results}

Of the 24 patients with young-onset hypertension who participated in the study, 15 were male, and nine were female, with a mean age of 31.7 (range: 19-40) years. The control group comprised 22 individuals, 12 males, and ten females, with a mean age of 30.2 (range: 18-39) years. The body mass index and the mean levels of low-density lipoprotein and triglyceride of the two groups are shown in Table 1. There were no significant differences between the patient and control groups in any of the variables examined (Table 1).

The mean level of YKL-40 significantly differed between the patient $(926.64 \pm 384.18$; range: 163.5 $1905.1 \mathrm{pg} / \mathrm{mL}$ ) and control groups (749.50 \pm 622.68 ; range: $42.71-1893.67 \mathrm{pg} / \mathrm{mL} ; \mathrm{P}<0.05)$. The mean level 
of vaspin in the patient group $(123.70 \pm 98.55 \mathrm{pg} / \mathrm{mL}$; range: $39.7-236 \mathrm{pg} / \mathrm{mL}$ ) was not significantly different from that in the control group $(106.36 \pm 75.49 \mathrm{pg} / \mathrm{mL}$; range: $18.8-231.88 \mathrm{pg} / \mathrm{mL} ; \mathrm{P}=0.531$ ) (Table 2).

The mean FMD in the patient group (6.72 \pm 3.52 ; range: $2.5-16)$ was significantly lower than that in the control group (11.89 \pm 3.04 ; range: 7.9-21.8; $\mathrm{P}<0.05$ ) (Table 2). The levels of YKL-40 were negatively correlated with FMD $(r=-0.679, \mathrm{P}<0.05)$.

\section{Discussion}

This study demonstrated for the first time that plasma YKL-40 concentration was high in patients with young-onset hypertension compared with normotensive subjects, and the higher plasma YKL-40 levels were associated with the deterioration of vascular function determined by FMD. These results provide evidence for the potential role of YKL-40 in the pathogenesis of young-onset hypertension and hypertension-related vascular injury.

The pathogenesis of essential hypertension is unknown due to the presence of multiple etiologies and the complexity of this disease. ${ }^{20}$ Experimental and clinical evidence indicates the critical role of oxidative stress and inflammation in the development of hypertension. There is an independent link between systemic inflammation and increased risk of hypertension. The inflammatory response in the vascular wall and oxidative stress plays an important role in the early stages of the development of hypertension. ${ }^{21-23}$ Oxidative stress caused by oxygen free radicals leads to the development of hypertension through endothelial dysfunction, vascular wall remodeling, and vascular inflammation. ${ }^{12}$ In the early stages of hypertension, patients are exposed to endothelial dysfunction in the microvascular system without clinically detectable target organ damage. Continuous increase in systemic pressure causes the premature aging of the microvascular system and frequent regeneration of endothelial cells, reducing the ability of endothelin to secrete factors, which leads to an imbalance in favor of vasoconstriction. ${ }^{24-26}$

The vascular endothelium plays a role in the production and secretion of various molecules that are involved in the adhesion of leukocytes to the vascular endothelium and the regulation of vascular permeability and vascular tone, and therefore injuries caused by hypertension lead to the development of vascular endothelial dysfunction. ${ }^{27}$ Although hypertension includes both endothelial dysfunction and inflammation in its pathophysiology, the degeneration of the vascular structure characterized by endothelial dysfunction may be both the cause and the result of hypertension. ${ }^{28,29}$ It is also known that endothelial dysfunction is associated with inflammation and contributes to hypertension. The plasma concentrations of proinflammatory cytokines have been reported to be higher in hypertensive patients. ${ }^{30}$

YKL-40 is a proinflammatory protein that has been proven to play a role in the pathogenesis of endothelial dysfunction. ${ }^{31}$ YKL-40 (human cartilage glycoprotein 39) is mainly secreted from macrophages,

Table 1. The demographic features of the patients with young-onset hypertension and normotensive controls.

\begin{tabular}{lccc}
\hline & $\begin{array}{c}\text { Patients }(\mathbf{n}=\mathbf{2 4}) \\
(\text { Mean } \pm \text { SD) }\end{array}$ & $\begin{array}{c}\text { Controls }(\mathbf{n}=\mathbf{2 2}) \\
\text { (Mean } \pm \text { SD) }\end{array}$ & P value \\
\hline Age (mean) & $31.7 \pm 8.7$ & $30.2 \pm 5.8$ & 0.592 \\
\hline Sex (male) & $15(62 \%)$ & $12(55 \%)$ & 0.442 \\
\hline Body mass index $\left(\mathrm{kg} / \mathrm{m}^{2}\right)$ & $27.3 \pm 3.31$ & $26.9 \pm 3.14$ & 0.114 \\
\hline Low-density lipoprotein $(\mathrm{mg} / \mathrm{dL})$ & $103.8 \pm 21.4$ & $102.2 \pm 20.6$ & 0.128 \\
\hline Triglyceride $(\mathrm{mg} / \mathrm{dL})$ & $193.2 \pm 25.6$ & $188.5 \pm 22.3$ & 0.168 \\
\hline
\end{tabular}

$\mathrm{SD}$, standard deviation.

Table 2. The mean levels of YKL-40, vaspin, and flow-mediated dilatation of the patients with young-onset hypertension and normotensive controls.

\begin{tabular}{lccc}
\hline & $\begin{array}{c}\text { Patients } \\
(\text { Mean } \pm \text { SD) }\end{array}$ & $\begin{array}{c}\text { Controls } \\
(\text { Mean } \pm \text { SD) }\end{array}$ & P value \\
\hline YKL-40 $(\mathrm{pg} / \mathrm{mL})$ & $926.64 \pm 384.18$ & $749.50 \pm 622.68$ & $<0.05$ \\
\hline Vaspin $(\mathrm{pg} / \mathrm{mL})$ & $123.70 \pm 98.55$ & $106.36 \pm 75.49$ & 0.531 \\
\hline FMD $(\%)$ & $6.72 \pm 3.52$ & $11.89 \pm 3.04$ & $<0.05$
\end{tabular}

$\mathrm{SD}$, standard deviation; FMD, flow-mediated dilatation. 
neutrophils, and vascular smooth muscle cells, and is significantly involved in remodeling of the extracellular matrix and in the maturation, adhesion, and migration of macrophages. The increased level of YKL-40 has been reported to be associated with lowgrade inflammatory conditions. ${ }^{32,33}$ In addition, the relationship between the YKL-40 level and blood pressure has been previously demonstrated. ${ }^{8}$

Vaspin, an adipokine inhibiting serine proteases, has been shown to have a protective effect on endothelial cells through increasing endothelial repair by endothelial progenitor cells and inhibiting the apoptosis of vascular endothelial cells. ${ }^{34,35}$ The previously shown effects of vaspin inhibiting tumor necrosis factor-mediated inflammatory responses and platelet-mediated growth factor migration through smooth antioxidant mechanisms in smooth muscle cells suggest that it may act as an anti-inflammatory agent. ${ }^{36}$ It has been reported that vaspin induces acetylcholine through the inhibition of acetylcholine esterase, it increases endothelial-dependent relaxation, and has a positive effect on nitric oxide (NO) bioavailability, which is important in the etiology of endothelial dysfunction. ${ }^{37,38}$ Vaspin has also been shown to inhibit the elevation of blood pressure by inhibiting peripheral arterial hypertrophy, possibly due to its effect on antioxidant and anti-inflammatory mechanisms. ${ }^{13}$ These results indicate that vaspin has preventive roles in the pathogenesis of hypertension.

In the literature, there is only one study on vaspin levels in young-onset hypertension patients, and it reports an increase in blood vaspin values in youngonset hypertension patients compared to normal controls. It was suggested that high vaspin levels might be a compensatory mechanism against hypertension. ${ }^{39}$ In our study, no significant difference was found between the patient and control groups in terms of vaspin values. Unlike our findings, the only other study available in the literature attributed the high level of vaspin produced from adipose tissue to the presence of obese patients in the sample.

The FMD of the brachial artery has emerged as an important method for demonstrating endothelium-dependent vasodilatation via $\mathrm{NO}$ in response to reactive hyperemia in order to assess vascular endothelial function. ${ }^{40}$ In this study, we found that FMD was decreased in patients with young-onset hypertension compared to the control group. Our findings confirm previous evidence that FMD is reduced in patients with essential hypertension, but this is also seen in young patients, suggesting that endothelial dysfunction begins to occur before adaptive changes to the vascular wall in response to high blood pressure. In our study, the YKL-40 level was found to be significantly higher in patients with young-onset hypertension. In addition, a negative correlation was observed between YKL-40 and FMD. Increased levels of YKL 40 and decreased
FMD values suggest that increased inflammation and endothelial dysfunction may play a role in the etiology of young-onset hypertension.

\section{Limitations of the study}

The first limitation was that it was a case-control study that did not involve any investigation into causality. Thus, it was not possible to clarify whether lower FMD and higher YKL-40 levels were the cause or result of hypertension. Secondly, the sample size of the study was relatively small, and larger prospective studies are needed to reveal the clinical significance of inflammation and endothelial dysfunction in hypertensive patients.

\section{Conclusions}

Decreased FMD and increased levels of YKL-40 were associated with endothelial dysfunction and inflammation in patients with young-onset hypertension, suggesting the role of these factors in the etiology of hypertension. To the best of our knowledge, this is the first study in literature to show elevated serum YKL40 levels, a potential biomarker of inflammation and vascular dysfunction in patients with young-onset hypertension.

\section{References}

1. Kearney PM, Whelton M, Reynolds K, et al. Global burden of hypertension: Analysis of worldwide data. Lancet 2005;365:217-23.

2. Messerli FH, Williams B, Ritz E. Essential hypertension. Lancet 2007;370:591-603.

3. Assadi F. The growing epidemic of hypertension among children and adolescents: A challenging road ahead. Pediatr Cardiol 2012;33:1013-20.

4. Drukteinis JS, Roman MJ, Fabsitz RR, et al. Cardiac and systemic hemodynamic characteristics of hypertension and prehypertension in adolescents and young adults: The Strong Heart Study. Circulation 2007;115:221-7.

5. Singh M, Mensah GA, Bakris G. Pathogenesis and clinical physiology of hypertension. Cardiol Clin 2010;28:545-59.

6. Harrison DG, Guzik TJ, Lob HE, et al. Inflammation, immunity, and hypertension. Hypertension 2011;57:132-40.

7. Kastrup J. Can YKL-40 be a new inflammatory biomarker in cardiovascular disease? Immunobiology 2012;217:483-91.

8. Ma WH, Wang XL, Du YM, et al. Association between human cartilage glycoprotein 39 (YKL-40) and arterial stiffness in essential hypertension. BMC Cardiovasc Disord 2012;12:35.

9. de Lemos JA, Morrow DA, Sabatine MS, et al. Association between plasma levels of monocyte chemoattractant protein-1 and long-term clinical outcomes in patients with acute coronary syndromes. Circulation 2003;107:690-5. 
10. Malinda KM, Ponce L, Kleinman HK, et al. Gp38k, a protein synthesized by vascular smooth muscle cells, stimulates directional migration of human umbilical veinendothelial cells. Exp Cell Res 1999;250:168-73.

11. Hida K, Wada J, Eguchi J, et al. Visceral adipose tissuederived serine protease inhibitor: a unique insulinsensitizing adipocytokine in obesity. Proc Natl Acad Sci U S A 2005;102:10610-5.

12. Montezano AC, Dulak-Lis M, Tsiropoulou S, et al. Oxidative stress and human hypertension: vascular mechanisms, biomarkers, and novel therapies. Can J Cardiol 2015;31:631-41.

13. Kameshima S, Sakamoto Y, Okada M, et al. Vaspin prevents elevation of blood pressure through inhibition of peripheral vascular remodelling in spontaneously hypertensive rats. Acta Physiol 2016;217:120-9.

14. Zieger K, Weiner J, Krause K, et al. Vaspin suppresses cytokine-induced inflammation in 3T3-L1 adipocytes via inhibition of NFkappaB pathway. Mol Cell Endocrinol 2018;460:181-8.

15. Qi D, Wang D, Zhang C, et al. Vaspin protects against LPS-induced ARDS by inhibiting inflammation, apoptosis and reactive oxygen species generation in pulmonary endothelial cells via the Akt/GSK3beta pathway. Int J Mol Med 2017;40:1803-17.

16. Raitakari OT, Celermajer DS. Testing for endothelial dysfunction. Ann Med 2000;32:293-304.

17. Anderson TJ, Uehata A, Gerhard MD, et al. Close relation of endothelial function in the human coronary and peripheral circulations. J Am Coll Cardiol 1995;26:1235-41.

18. Corretti MC, Anderson TJ, Benjamin EJ, et al. International Brachial Artery Reactivity Task Force. Guidelines for the ultrasound assessment of endothelial-dependent flow-mediated vasodilation of the brachial artery: a report of the International Brachial Artery Reactivity Task Force. J Am Coll Cardiol 2002;39:257-65.

19. Rodriguez-Miguelez P, Seigler N, Harris RA. Ultrasound assessment of endothelial function: a technical guideline of the flow-mediated dilation test. J Vis Exp 2016;110:54011.

20. Dasinger JH, Davis GK, Newsome AD, Alexander BT. Developmental programming of hypertension: physiological mechanisms. Hypertension 2016;68:826-31.

21. Usui T, Okada M, Hara Y, Yamawaki H. Death-associated protein kinase 3 mediates vascular inflammation and development of hypertension in spontaneously hypertensive rats. Hypertension 2012;60:1031-9.

22. Usui T, Okada M, Hara Y, Yamawaki H. Eukaryotic elongation factor 2 kinase regulates the development of hypertension through oxidative stress-dependent vascular inflammation. Am J Physiol Heart Circ Physiol 2013;305:756-68.

23. Gökaslan S, Özer Gökaslan Ç, Demirel E, Çelik S. Role of aortic stiffness and inflammation in the etiology of young-onset hypertension. Turk J Med Sci 2019;49: 1748-53.

24. Tang EH, Vanhoutte PM. Endothelial dysfunction: a strategic target in the treatment of hypertension? Pflugers Arch 2010;459:995-1004.
25. Stankevicius E, Martinez AC, Mulvany MJ, Simonsen U. Blunted acetylcholine relaxation and nitric oxide release in arteries from renal hypertensive rats. J Hypertens 2002;20:1571-9.

26. Feihl F, Liaudet L, Levy BI, Waeber B. Hypertension and microvascular remodelling. Cardiovasc Res 2008; 78:274-85.

27. Deanfield JE, Halcox JP, Rabelink TJ. Endothelial function and dysfunction: testing and clinical relevance. Circulation 2007;115:1285-95.

28. Flammer AJ, Anderson T, Celermajer DS, et al. The assessment of endothelial function: from research into clinical practice. Circulation 2012;126:753-67.

29. Srivastava K, Narang R, Bhatia J, Saluja D. Expression of heat shock protein 70 gene and its correlation with inflammatory markers in essential hypertension. PLoS One 2016;11:e0151060.

30. Yasunari K, Maeda K, Nakamura M, Yoshikawa J. Oxidative stress in leukocytes is a possible link between blood pressure, blood glucose, and C-reacting protein. Hypertension 2002;39:777-80.

31. Rathcke CN, Vestergaard H. YKL-40, a new inflammatory marker with relation to insulin resistance and with a role in endothelial dysfunction and atherosclerosis. Inflamm Res 2006;55:221-7.

32. Rathcke CN, Vestergaard H. YKL-40-an emerging biomarker in cardiovascular disease and diabetes. Cardiovasc Diabetol 2009;8:61.

33. Johansen JS. Studies on serum YKL-40 as a biomarker in diseases with inflammation, tissue remodelling, fibroses and cancer. Dan Med Bull 2006;53:172-209.

34. Nakatsuka A, Wada J, Iseda I, et al. Visceral adipose tissue-derived serine proteinase inhibitor inhibits apoptosis of endothelial cells as a ligand for the cell-surface GRP78/voltage-dependent anion channel complex. Circ Res 2013;112:771-80.

35. Jung CH, Lee WJ, Hwang JY, et al. Vaspin protects vascular endothelial cells against free fatty acid-induced apoptosis through a phosphatidylinositol 3-kinase/Akt pathway. Biochem Biophys Res Commun 2011;413:264-9.

36. Phalitakul, S, Okada M, Hara Y, Yamawaki H. A novel adipocytokine, vaspin inhibits platelet-derived growth factor-BB-induced migration of vascular smooth muscle cells. Biochem Biophys Res Commun 2012;423: 844-9.

37. Kameshima S, Yamada K, Morita T, et al. Visceral adipose tissue-derived serine protease inhibitor augments acetylcholine-induced relaxation via the inhibition of acetylcholine esterase activity in rat isolated mesenteric artery. Acta Physiol (Oxf) 2016;216:203-10.

38. Jung CH, Lee WJ, Hwang JY, et al. Vaspin increases nitric oxide bioavailability through the reduction of asymmetric dimethylarginine in vascular endothelial cells. PLoS One 2012; 7:e52346.

39. Zlatkina V. Vaspin levels and carbohydrate status in young patients with hypertension and obesity. Georgian Med News 2016;259:18-22.

40. Bianchini E, Giannarelli C, Bruno RM, et al. Functional and structural alterations of large arteries: methodological issues. Curr Pharm Des 2013;19:2390-400. 